\title{
SimEx: Simulation EXERCISES ON HUMANitARIAN CRISIS
}

\author{
Wook-Sung Yoo \\ Department of Software Engineering \\ Fairfield University \\ Fairfield, CT 06824 \\ wyoo@fairfield.edu
}

Abstract - A software engineering capstone project team at Fairfield University developed SimEx (Simulation Exercises on Humanitarian Crisis), a database driven web application for the JUHAN (Jesuits University Humanitarian Action Network) community. The objectives of the project were to educate students on humanitarian actions and to enhance their knowledge on how to react at the time of a crisis. SimEx is accessible to anyone in the JUHAN community around the world and facilitates interaction among instructors, researchers, and students. The software allows for the sharing of simulation exercise scenarios and provides students with simulation exercises on humanitarian actions without any boundaries. SimEx also provides a discussion board to the JUHAN community to facilitate communication and idea sharing. SimEx was implemented in PHP with a MySQL database and several additional PHP plug-ins. In this paper, the issues, process, and outcome of the collaborative service learning project between academia and community is detailed along with a discussion of the future direction of SimEx.

Index Terms -JUHAN, Simulation, Service Learning, Web Application

\section{INTRODUCTION}

Service-learning is a pedagogical practice that links academic study and community-based service so that each is strengthened and both are transformed. ${ }^{i}$ Inspired by the Jesuit Catholic educational mission of Fairfield University, the service learning program at Fairfield University facilitates connections between focused academic learning that meets disciplinary standards for rigor, with meaningful and appropriate service that addresses needs identified by and with communities. ${ }^{\text {ii }}$ As civic engagement has become more prominent in undergraduate education in the new millennium, several courses at Fairfield University have been designated as service learning courses by the Office of Service Learning at Fairfield University. ${ }^{\text {iii,iv }}$ While traditional engineering programs are more focused on technical development and not on preparing sociallyresponsible engineers with a strong sense of citizenship, the School of Engineering at Fairfield University decided to integrate a service learning component into its curriculum in 2009 by designating the Capstone Project course as its first service learning course. ${ }^{v}$ The capstone project course is a two-semester, team-project course offered by the Software Engineering department for students to work on large scale, real world software projects. The course is designed to improve students' communication skills, team work, and leadership skills and focuses on building professionalism, good working attitude, and ownership of the project through a series of lectures and actual practice in the class. The service component in the course is optional. The software engineering program decided to provide service learning opportunities as an option within the course. Some groups of students chose to work on service learning 
capstone projects while others worked on more typical industry projects. The service-learning option in the Capstone Project course exposes software engineering students to the communityengaged learning model and provides service to community organizations which are in great need of quality software applications to facilitate their mission. More courses in the Software Engineering department are now designated as service-learning courses and various software projects have been successfully delivered to our community partners over the past several years. $^{\text {vi }}$

The Software Engineering Capstone Project course covers the entire software development lifecycle: requirements gathering, requirements analysis, design, prototyping, implementation, testing, deployment and maintenance. Traditionally, student teams use to engage in large scale real-world projects with local industry and government agencies. With the service learning component now part of this course, some students now gain additional benefits. In collaboration with community organizations, students harness the tools of the academic discipline and deepen their understanding of the social, political, and economic issues that contribute to the challenges faced by groups and communities and of larger social inequalities and injustices. Service learning projects especially offer an opportunity for software engineering students to communicate and work with non-technical people in the partner organization, which is usually not possible in industry projects.

This paper describes the development of a web-based application called SimEx (Simulation Exercises on humanitarian crisis) developed by a group of Capstone Project course students in 2012 as a service learning project for the Jesuit Universities Humanitarian Action Network (JUHAN) community. JUHAN educates and prepares students to deal with complex humanitarian crisis issues. To help achieve this goal, SimEx was developed at Fairfield University inspired by Professor William Stover's Conflict Resolution Simulation exercise. ${ }^{\text {vii }}$ SimEx is an online tool for instructors to provide humanitarian crisis exercises to students to realize the complexity of humanitarian crisis issues. Faculty can prepare their own humanitarian crisis scenario using instructor tools provided or they can use existing simulation exercises developed by other faculty that suit the goals and themes of their courses. Students are asked to think critically and address complex problems. Active and collaborative learning are hallmarks of JUHAN and these simulation exercises. SimEx is an open, online tool accessible to any JUHAN faculty/staff/students internationally. A scenario created by a faculty in Europe can be used by other faculty in Africa. Students from multiple countries can take a JUHAN course under the guidance of a faculty long distance and share information through a built-in discussion board. SimEx is designed to facilitate communication among members of the JUHAN community. In the following sections, background information is provided and other existing simulation tools are introduced. Then, the requirements for the SimEx are identified and the design and implementation of SimEx is discussed. Finally, the usability testing results, servicelearning aspect of the project, and future enhancements are discussed.

\section{BACKGROUND}

The Jesuit Universities Humanitarian Action Network (JUHAN) is a collaboration of faculty, staff, and students at Jesuit universities both domestic and international. ${ }^{\text {vii }}$ The members of the network aim to raise awareness on Jesuit campuses of the meaning of humanitarian response and its relation to the Jesuit ideology of being "men and women for others." The principal focus of JUHAN is undergraduate education and one of JUHAN's goals is to incorporate humanitarian 
action issues into the classroom curricula. ${ }^{\text {ix }}$ To improve students' learning in the context of humanitarian engagements, the JUHAN organization offers simulation resources to be used in the classroom. ${ }^{\mathrm{x}}$ Current simulation tools include: (1) International Humanitarian Crisis Simulation: Darfur, provided by Santa Clara University, (2) Millennium Village Simulation provided by Columbia University, and (3) ReliefSim provided by Columbia University's Center for New Media Teaching.

International Humanitarian Crisis Simulation is a simulation tool in which participants represent international and non-governmental organizations as well as nation states involved in the humanitarian crisis. Individuals do research on these organizations as well as their roles within them, writing a paper that helps them empathize with their team's view of the crisis. They are presented with a scenario that requires responses and provides online connections to facilitate decision making and negotiations. The teams then react, using "moves" that simulate the cooperation and contention occurring among groups involved in emergency relief. ${ }^{\mathrm{xi}}$

The Millennium Village Simulation is a web-based simulation tool of economics and survival for one family and their village in a sub-Saharan African village provided by Columbia University's Center for New Media Teaching and Learning. In a virtual world of extreme poverty, disease, and environmental variability, students are challenged to help a family of two survive and prosper over a fifty-year period. By making decisions regarding the family's allocation of time and financial resources, students develop a greater understanding of the manifold disciplines, such as agronomy, nutrition, economics, epidemiology, public health and development management, that work together to constitute sustainable development. ${ }^{\text {ii }}$

ReliefSim is a simulation tool of a humanitarian emergency scenario also provided by Columbia University's Center for New Media Teaching and Learning. Students play the role of a health relief director. Each student or group has a team of people they assign to assess the situation and attempt to manage the health concerns of the crisis. The educational goal concerns the challenges arising from prioritizing assessments and interventions while saving lives in moments of crisis. The simulation was originally designed to train humanitarian workers to manage complex emergencies. xiii

In 2011, JUHAN FPLC (Faculty Professional Learning Community) at Fairfield University examined various simulation tools to enhance the knowledge of students on how to react at the time of crisis and considered International Humanitarian Crisis Simulation as a simulation exercise tool to be used in JUHAN-designated courses at Fairfield University. JUHAN FPLC, however, experienced some limitations in the usage of International Humanitarian Crisis Simulation due to the difficulty in course management with different semester systems between Fairfield University and Santa Clara University, the lack of user management outside of the Santa Clara University campus, and the static approach of the simulation exercise management. To resolve the issues, the JUHAN FPLC team decided to work with the software engineering department at Fairfield University to develop a new online simulation exercise tool to be accessible by anyone in the JUHAN community around the world to facilitate interactions among instructors, researchers, and students to share simulation exercise scenarios and to educate students on humanitarian actions regardless of school system structure and other restrictions.

\section{IMPLEMENTATION OF SIMEX}

Four out of eighteen students in the capstone project class in 2011-12 academic year were selected for the Service-Learning project team to develop SimEx. The team followed the 
Software Development Life Cycle (SDLC) but decided not to adopt agile process in the software development since some team members were working full time at other companies and their timely involvement and close collaboration were not always possible. Regular weekly meetings with the JUHAN FPLC faculty were held throughout the fall semester to gather and analyze the requirement of the project. JUHAN FPLC faculty communicated actively with JUHAN community to confirm the requirements. Based on the input from stakeholders (JUHAN FPLC faculty), the use case diagrams were created to support four different types of users as shown in Figure 1.

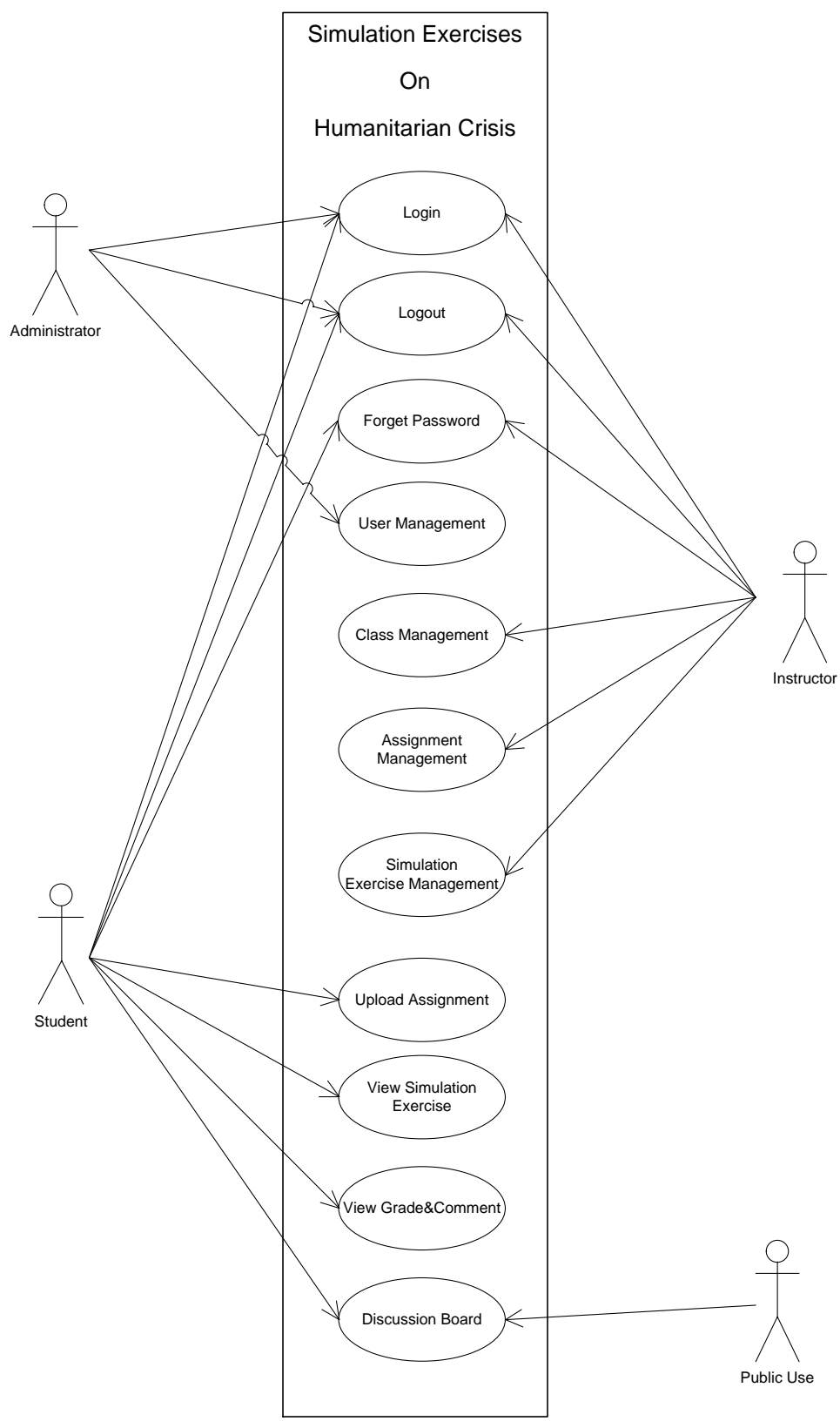

FIGURE 1

USE CASE DIAGRAM FOR SIMEX 
Database design with entity-relationship (ER) diagrams, flow diagrams, and activity diagrams were reviewed by the stakeholders. Figure 2 displays all tables, their fields, and relationships in SimEx database. The prototype of SimEx designed using MS Visio was approved at the end of the Fall semester.

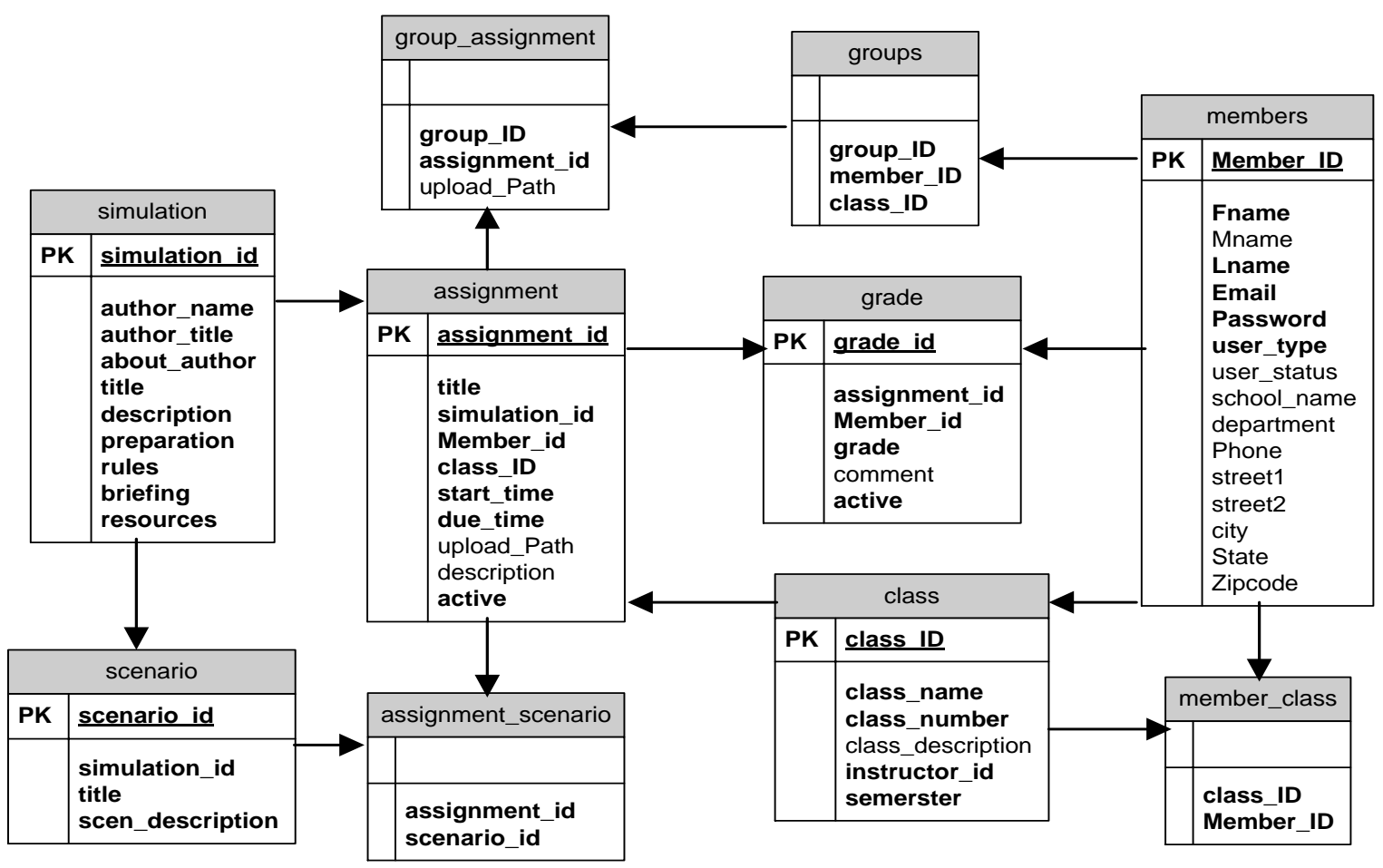

\begin{tabular}{|l|l|l|l|l|}
\hline \multicolumn{2}{|c|}{} & \multicolumn{2}{c|}{ forum_question } \\
forum_answer & question id & PK & id \\
\hline & $\begin{array}{lll}\text { a_id } \\
\text { a_name } \\
\text { a_email } \\
\text { a_answer } \\
\text { a_datetime }\end{array}$ \\
& & $\begin{array}{l}\text { topic } \\
\text { detail } \\
\text { name } \\
\text { email } \\
\text { datetime } \\
\text { view } \\
\text { reply }\end{array}$ \\
\hline
\end{tabular}

FIGURE 2

DATABASE SCHEMA OF SIMEX

Before starting implementation, the team investigated several options in its development platform. Many required components of the application including course management and assignment management are similar to the features of existing course management system (CMS) such as Black Board. However, SimEx is intended for the entire JUHAN community which uses different semester systems and CMSs. As a result, integration of the application with 
a specific CMS was not a good option. Considering the need for possible future updates and deployment of the application on different platforms at other schools, the team decided to use the free, platform compatible, open source environments of PHP and MySQL. PHP also provides strong user community support and many free extensions including a discussion board (forum), plug-ins, and editing tools required for the project. Most students in the team were familiar with PHP programming language. The team completed the development of SimEx using PHP and MySQL and deployed SimEx by the end of the Spring semester. As shown in the snapshot of SimEx home page in Figure 3, several static pages were developed to provide information of the mission of JUHAN and the background information of SimEx with useful links. Anyone who has interest in using SimEx for a class can contact the administrator of SimEx through the "Contact Us" link.

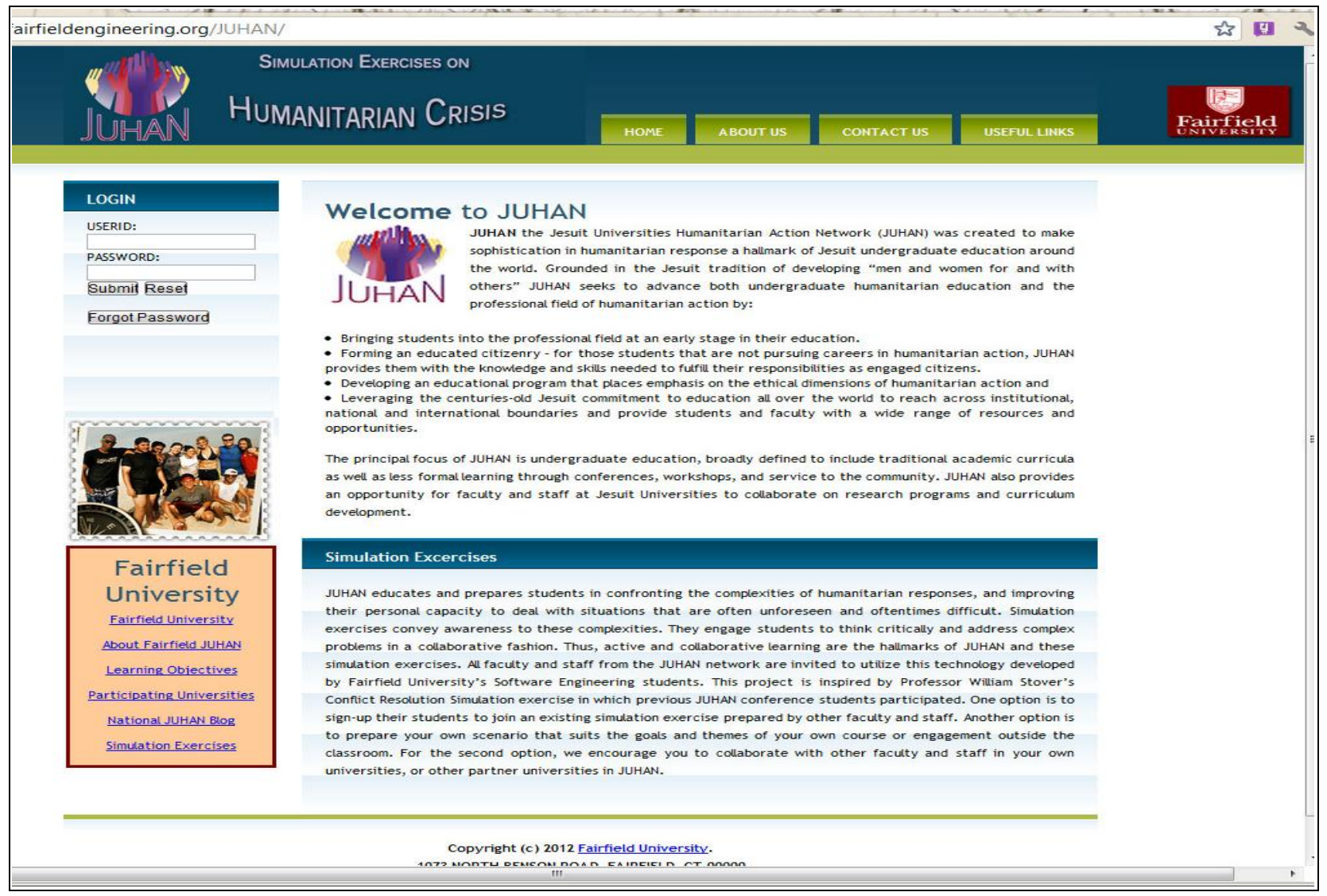

FIGURE 3

HOME PAGE OF SIMEX

SimEx consists of three major components: (1) A PHP Application running on Apache Web server, (2) Add-on of PHP Plug-ins, and (3) MySQL Database. Figure 4 presents an overview of the system components of SimEx. 


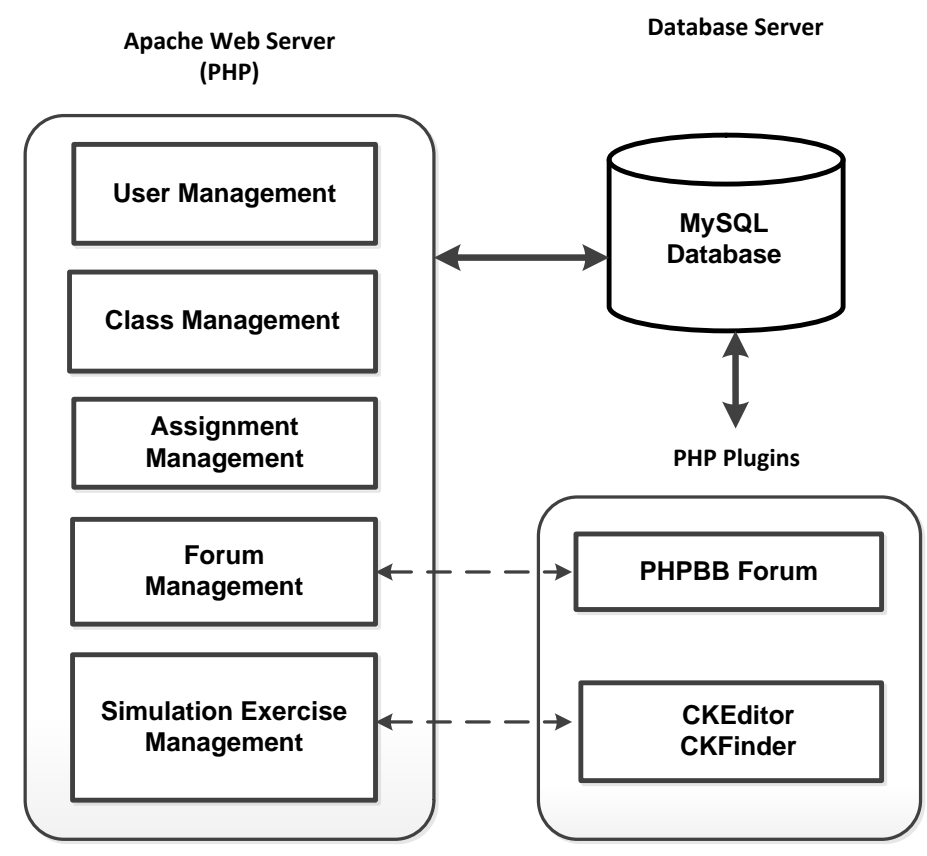

FIGURE 4

SYSTEM OVERVIEW OF SIMEX

PHP Application in Apache web server is the key component to support SimEx which is further divided into five components: (1) User Management, (2) Class Management, (3) Assignment Management, (4) Forum Management, and (5) Simulation Exercise Management. These password protected components support four different types of users as shown in use case diagram in Figure 1. Details of each component will be described below.

\section{(1) User Management}

The Administrator user communicates with any faculty/researcher and creates Instructor user accounts as shown in Figure 5. Once an Instructor account is created by Administrator, a confirmation email is sent to the Instructor with login information. The Instructor can create Student accounts in the class by either importing a spreadsheet of student's information or entering student's information manually. Instructor can also update Student's information later. 


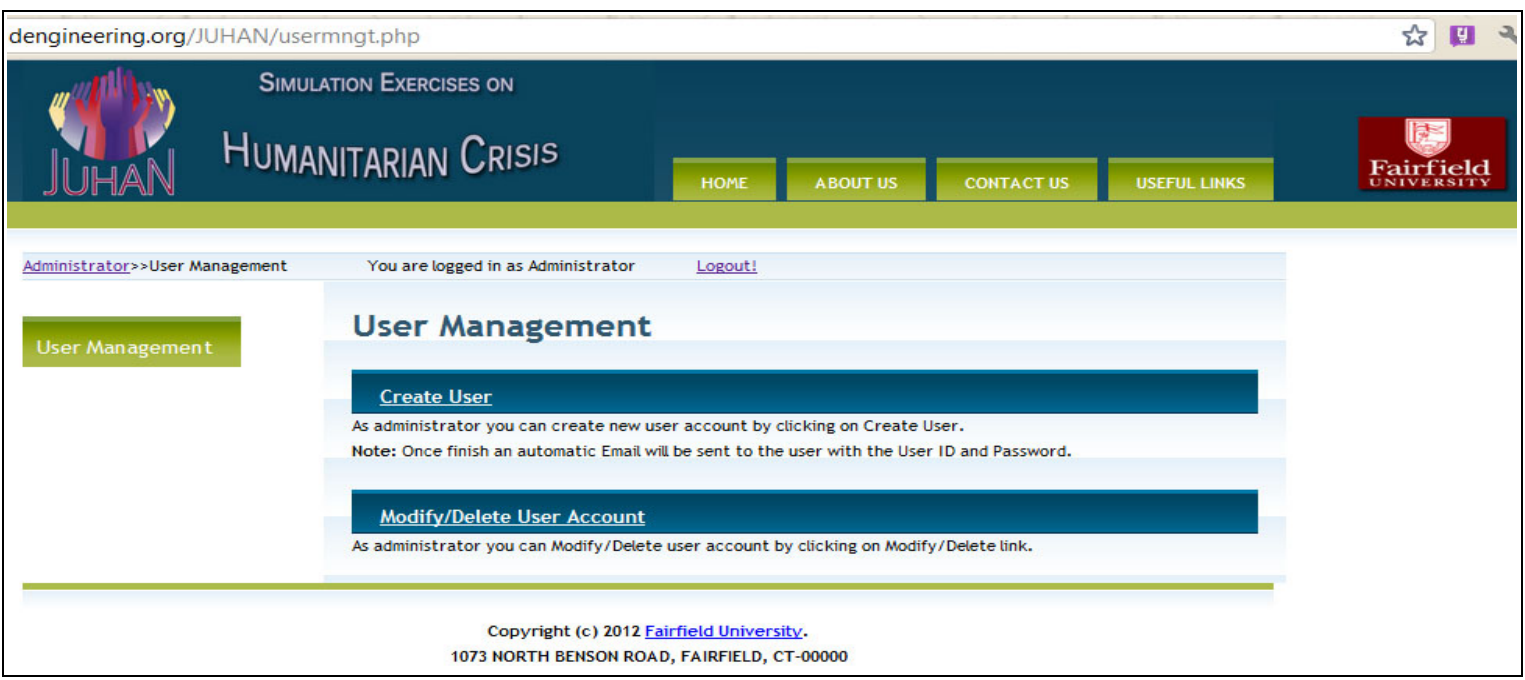

\section{FIGURE 5}

USER MANAGEMENT PAGE FOR ADMINISTRATOR USER IN SIMEX

\section{(2) Class Management}

The Instructor in the class management component can manage classes by adding new classes or by modifying/deleting existing classes in a selected term. The Instructor, then, can select and put students to certain classes created by User Management component.

\section{(3) Assignment Management}

The Instructor can create new assignments or modify/delete existing assignments. The Instructor may select and use any Simulation Exercise for an assignment which may be created by the Instructor herself/himself or any other instructor/researchers through Simulation Exercise Management component. The Instructor can assign an individual assignment or a group assignment. Students or groups of students can view guidelines for assignments, download Simulation Exercises, and upload their work to the system before its due set by the Instructor. Then, the Instructor can download student's work and grade the students on their assignments. Students can view the grade once grade is given by the Instructor. Figure 6 shows a snapshot of Assignment Management page of the Instructor. 
International Journal for Service Learning in Engineering Vol. 8, No. 1, pp. 48-61, Spring 2013

ISSN 1555-9033

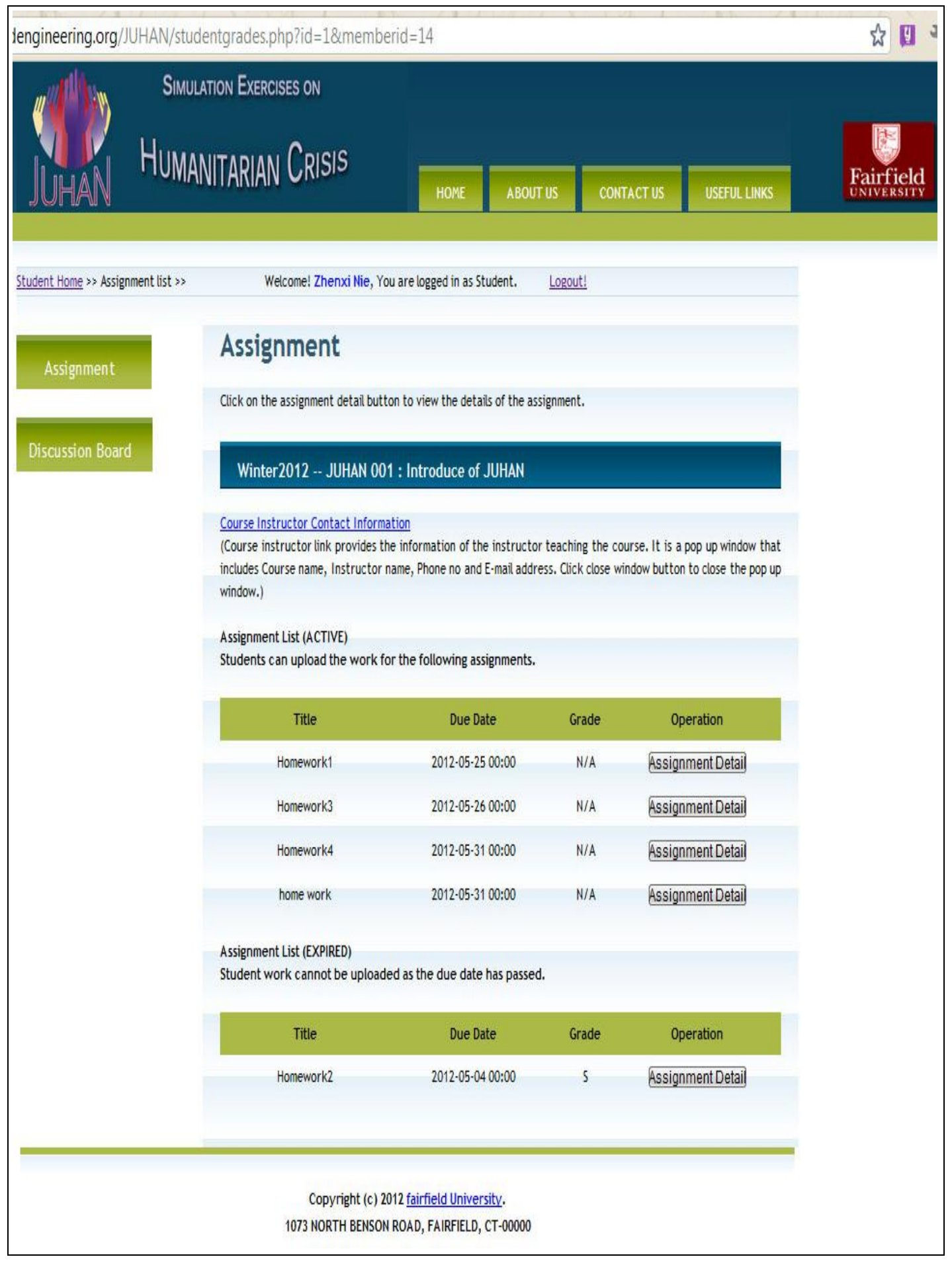

FIGURE 6

ASSIGNMENT MANAGEMENT PAGE IN SiMEX 


\section{(4) Forum Management}

The Forum or Discussion Board is provided to be accessible to all users including general internet user to discuss the topics in the class or share information on any topics related to humanitarian crisis as shown in Figure 7. SimEx integrates a free phpBB Forum plugin in the system to support the discussion board.

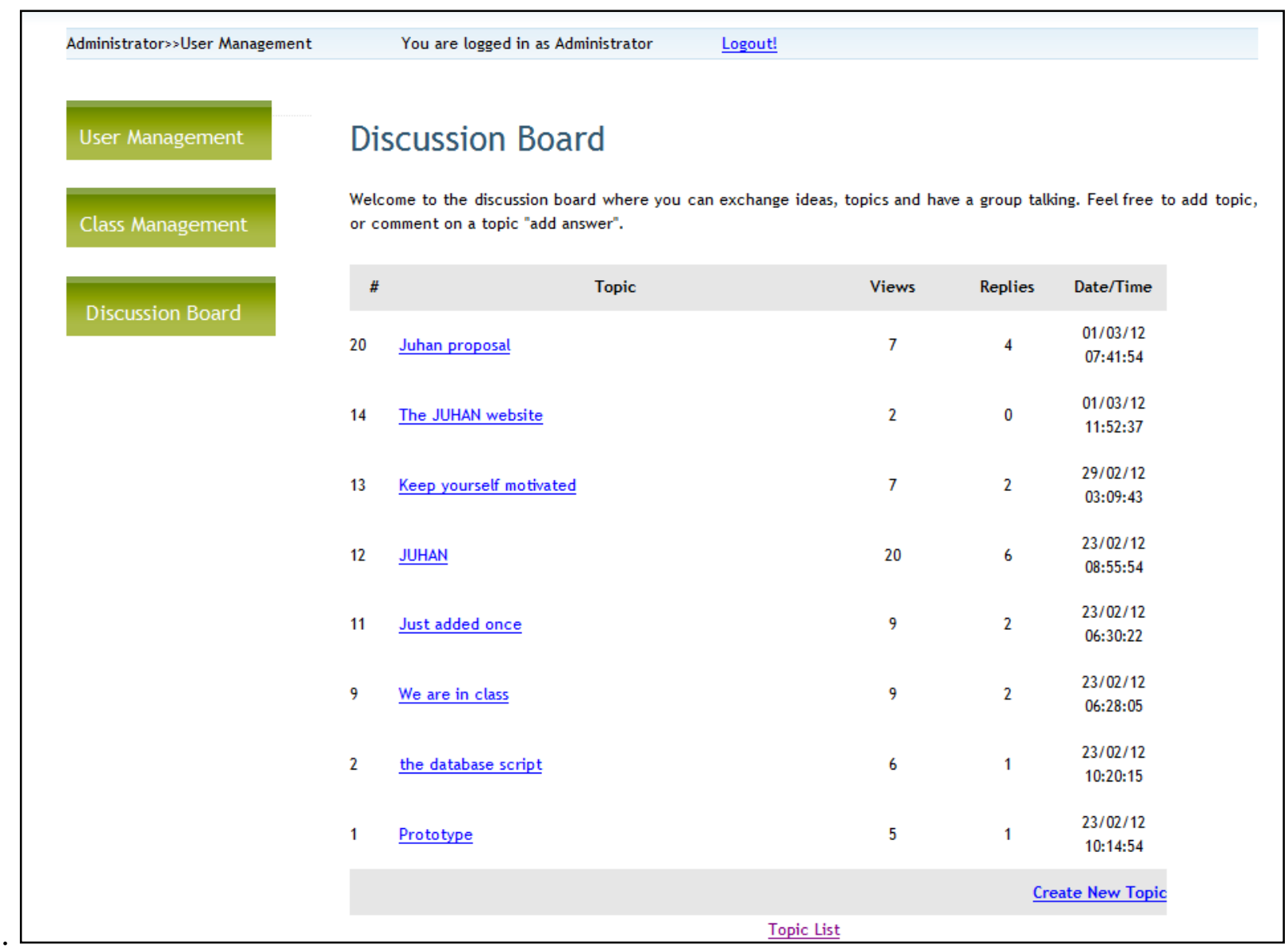

FIGURE 7

\section{DISCUSSION BOARD IN SIMEX}

\section{(5) Simulation Exercise Management}

The Instructor can create a new Simulation Exercise or modify/delete existing Simulation Exercises which was created by himself/herself. However, any Simulation Exercise created by other Instructor cannot be modified. The Simulation Exercise Management component in SimEx provides an editor for instructors to create a new and to edit existing Simulation Exercise easily integrating CKEditor, as a PHP plugin, which provides a text editor component to be used as part of web applications and web sites. As shown in Figure 8, the Instructor user can easily add/modify/delete text, pictures, sounds, or videos to the editing box with a drag-and-down functionality. SimEx also uses CKFinder PHP plugin for the web file manager. With agreement from JUHAN faculty involved, SimEx currently includes several Simulation Scenarios created 
by the faculty at Fairfield University and Santa Clara University such as the Cuban Missile Crisis. $^{\text {xiv }}$
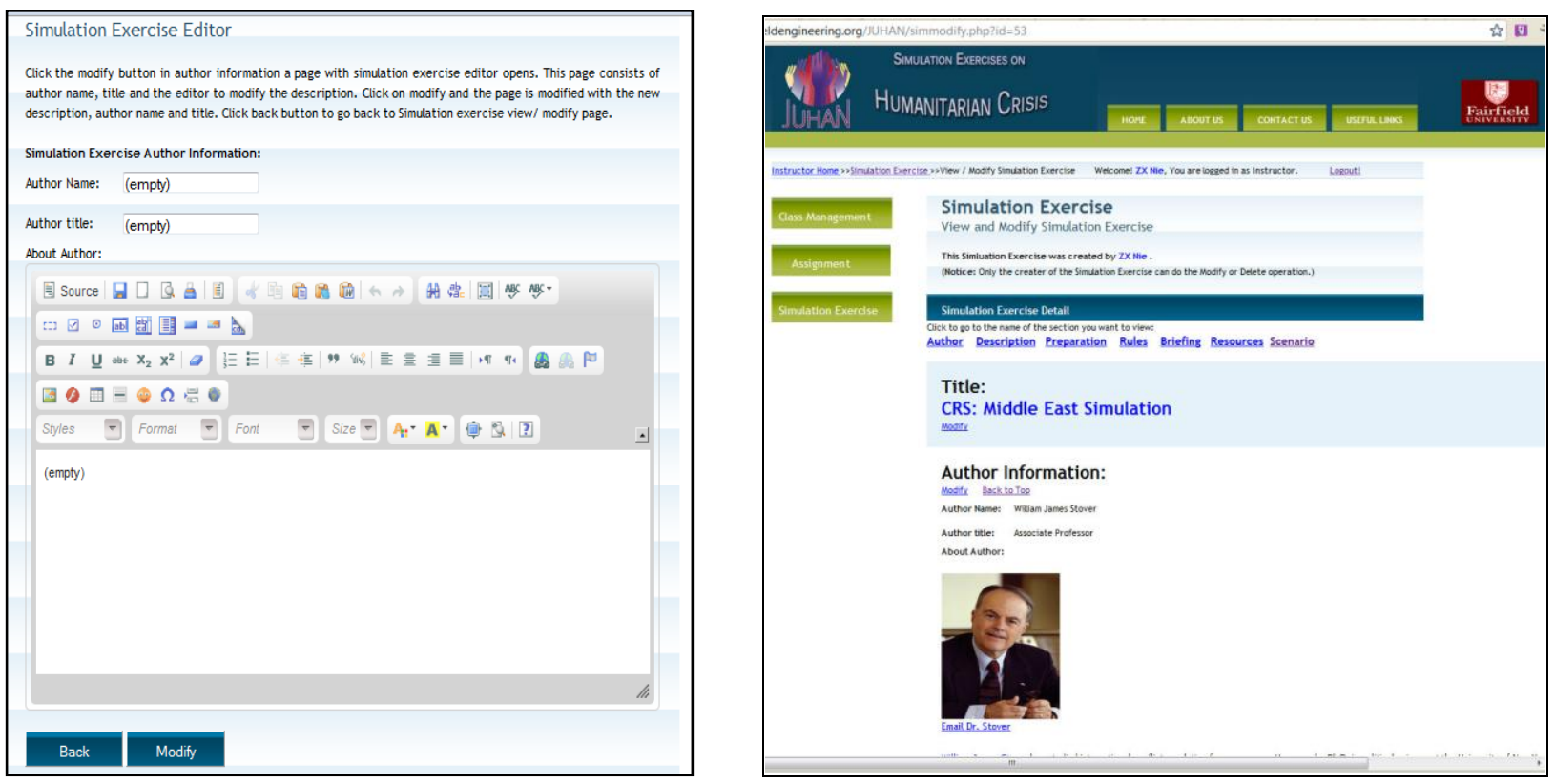

FIGURE 8

\section{A TEXT EDITOR AND A SAMPLE SIMULATION EXERCISE CREATED BY SIMULATION EXERCISE MANAGEMENT COMPONENT IN SIMEX}

Another important component of SimEx is the MySQL database. All Simulation Exercises are stored in a database to update and manage information easily. Information such as user, class, assignments and grades are also saved in the database.

\section{USABILITY TESTING}

SimEx was presented at the JUHAN Simulation Workshop in the JUHAN 3rd Annual Conference in June 2012 and usability testing was conducted. ${ }^{\mathrm{Xv}}$ All faculty, Staff, and students from the JUHAN conference attendants were invited and twelve people joined the JUHAN Simulation Workshop. The goal of the workshop was to demonstrate and provide training to the participants on how to use SimEx. The workshop consisted of two parts. The presenters of the program had a quick tour of SimEx demonstrating how to use SimEx with exercise examples. Then, participants were paired up and hand-on practice ensued. One partner acted as an instructor by creating an exercise using SimEx and grading student's response while the other acted as a student answering the exercise questions and review the grade given by the teacher. Then, the roles were switched. The usability testing was followed to evaluate SimEx to measure the effectiveness, efficiency, and satisfaction of the application to ensure the application is accurate, complete, comfortable to use, and acceptable to its users. ${ }^{\text {xi }}$ Usability was broken into five areas: learn-ability, efficiency, memorability, errors, and satisfaction. ${ }^{\text {xvii }}$ Participants were asked to rate $\operatorname{SimEx}$ on a scale of 0 (worst) to 5 (best) by answering eight questions in four categories: (1) the ease of learning SimEx and access to information, (2) the intuitiveness of the navigation, (3) the efficiency of the site including questions, (4) the degree of satisfaction 
including look and feel and usefulness of the application overall. The results show that the average rate, across all eight usability questions, was 4.6/5.0, demonstrating a high acceptance rate. The actual usability test questions and their average ratings are presented in Table 1.

TABLE I

USABILITY TEST QUESTIONS AND RATING RESULTS OF SIMEX

\begin{tabular}{lc}
\hline \multicolumn{1}{c}{ Questions } & Average Rating \\
\hline You were able to locate different pages specified below easily & 4.5 \\
\hline You could access the pages easily & 4.7 \\
\hline The site was intuitive and easy to use & 4.8 \\
\hline You found the site visually pleasing & 4.3 \\
\hline Your experience of response time of the page & 4.0 \\
\hline You felt like the application made logical sense & 4.6 \\
\hline This application is useful for JUHAN education & 4.9 \\
\hline You will use this application for your class if available & 4.7 \\
\hline
\end{tabular}

A few comments were collected requesting improvement in: (1) speed up the response time, (2) discussion board implementation on each class rather than one discussion board for the whole application. Overall, the response of participants was very positive.

\section{STUDENTS' LEARNING}

Reflection is an important activity in service-learning courses to connect service experience with course objectives. ${ }^{\text {xviii }}$ It promotes learning about larger social issues, develops students' evaluative thinking skills and reflective judgment. ${ }^{\text {xix }}$ Following the reflection activity guideline, writing assignments were regularly given to students throughout the course providing students an opportunity to examine and reassess their personal value systems. ${ }^{x x}$ After the completion of the Capstone Project, a survey with five questions below was given to students involved in SimEx projects:

Q1: Did your understanding of humanitarian crises improve because of this project?

Q2: Was this project helpful in linking your field of software engineering to the field of humanitarianism?

Q3: Did this project make you reflect on the efficacy of your individual and collective action in a social problem?

Q4: Did this project make you feel more connected to the programs in Fairfield

University outside of the School of Engineering?

Q5: How did this project contribute to your personal growth as a student?

Students' responses to the questions were very positive. On a scale of 1 (strongly disagree) to 5 (strongly agree), the average score on Q1 was 4.8, 4.3 on Q2, 4.8 on Q3, and 4.3 on Q4. This demonstrated that the service-learning component of this project generated student interest in the community and encouraged students to see their profession in different view. The survey results show students gained deeper understanding on humanitarian action and its importance through 
the project and the conversation with JUHAN FLPC faculty in weekly meetings seemed to influence students to realize their role in the community as software engineers.

While improving research and technical skills, students also had an opportunity to learn the importance of technical communication in verbal and written format through the real world projects. Students were usually surrounded by individuals with high levels of technical proficiency. However, the clients of service learning projects were mostly non-technical people and the students involved in the service learning projects had opportunity to collaborate with the clients in a non-technical fashion as well. The main stakeholders of SimEx project were JUHAN FPLC faculty who were mostly from the humanities or social science programs. The students learned how to communicate with them using non-technical terms. In addition to the required technical Capstone Project document, the students in SimEx project also created a user manual for Administrator and Instructor users which helped students develop the technical writing skills required to communicate to a broad audience.

\section{CONCLUSIONS}

We successfully developed Simulation Exercises on Humanitarian Crisis (SimEx), a dynamic interactive web application for JUHAN community, using PHP/MySQL and deployed it at http://www.fairfieldengineering/JUHAN to provide students and instructors to access the online simulation exercises to learn about humanitarian situations and practices. Instructors can securely log in, set up classes, create simulation exercises, and provide assignments to students. Students can review simulation exercises, work on given assignments, and view their grades. This interactive web application provides an interface for JUHAN community to share simulation exercises and exchange information and ideas through a built-in discussion board. Since SimEx is easily accessible by faculty, researchers, and students world-widely, it will help develop interest in humanitarian action and its education in community. SimEx is currently test-run by JUHAN classes at Fairfield University and is expected to be improved over extended time periods based on the feedbacks from the JUHAN faculty. Follow-up studies will be conducted to measure the contribution of the project to the community.

\section{ACKNOWLEDGEMENT}

Our thanks to graduate students in capstone project course, Zhenxi Nie, Khalid Said Neo, Lavanya Kudumula, Anupama Komaravolu, developing SimEx and Dr. Ana Siscar and other faculty in JUHAN FPLC who initiated and supported this project.

\section{REFERENCES}

i Robert G. Bringle, Julie A. Hatcher, "A Service-Learning Curriculum for Faculty", Michigan Journal of Community Service-Learning. Article 12, (1995): 112-122.

ii Office of Service Learning at Fairfield University, http://www.fairfield.edu/osl/index.html (accessed December 2012).

iii Levine, Myron A. "Seven Steps to Getting Faculty Involved in Service-Learning: How a Traditional Faculty Member Came to Teach a Course on "Voluntarism, Community, and Citizenship," Journal Citation: Michigan Journal of Community Service-Learning. v1 n1, (1994): 110-14. 
iv Barbara Jacoby, Civic Engagement in Higher Education: Concepts and Practices, (Hoboken, NJ: Jossey-Bass, Wiley, 2009).

v Nihad Dukhan and Mark Shumack, "A Service-Learning Experience in Engineering and Its Impact on Students," American Society of Engineering Education, (2000).

vi Amalia Rusu and Jennifer Lawlor. "Connecting Campus and Community through Web Development Service-Learning Projects," 40th ASEE/IEEE Frontiers in Education Conference, (2010), Washington, DC.

vii “Conflict Resolution Simulation” www.scu.edu/crs (Spring 2006)

viii JUHAN, www.juhanproject.org/about (accessed December 2012).

vi JUHAN Resources, For Faculty Interested in Teaching About Humanitarian Efforts, http://www.juhanproject.org/resources/ (accessed December 2012).

x JUHAN Resources, Faculty Simulation Resources, http://www.juhanproject.org/resources/ (accessed December 2012).

xi International Humanitarian Crisis: Darfur, Santa Clara University, http://www.scu.edu/crs/index.cfm (Spring 2010).

xii Millenium Village Simulation, Columbia University, http://mvsim.ccnmtl.columbia.edu/accounts/login/?next=

/login\%3Fdestination\%3Dhttp\%253A//mvsim.ccnmtl.columbia.edu/ (accessed December 2012).

xiii ReliefSim, Columbia University, http://ccnmtl.columbia.edu/projects/reliefsim/ (accessed December 2012).

xiv William James Stover, "Simulating the Cuban Missile Crisis: Crossing Time and Space in Virtual Reality", International Studies Perspectives (2007) 8, pp 111 (9).

xv Wook-Sung Yoo, Khalid Said, Sai Anupama Komaravolu, Lavanya Kudumula. "JUHAN Care Simulator," JUHAN 3rd Annual Conference, Fairfield University, June 12 - 15, 2012

xvi Scowen, G., \& Regenbrecht, H. (2009). Increased popularity through compliance with usability guidelines in E-learning web sites, International Journal of Information Technology and Web Engineering.

xvii Nielsen, J., \& Loranger, H. (2006). Prioritizing Web Usability, New Riders Press.

${ }^{x v i i i}$ Christopher Koliba, "Assessing Reflection Assignments for Public Affairs Courses: Implications for Educating Reflective Practitioners," Journal of Public Affairs Education, (2004) V. 4, 295-309.

xix Slivovsky, DeRego, and Jamieson, "Developing the reflection component in the EPICS model of engineering service-learning," Proc. 33rd ASEE/IEEE Frontiers in Education Conference (2003).

xx Julie A. Hatcher and Robert G. Bringle, "Reflection: bridging the gap between service and learning," College Teaching, v45, no. 4 (1997), 153 - 159. 